\title{
Microencapsulation of Potassium Phosphate in Chitosan and the Effect of Spray Drying Operating Variables on the Particle Size
}

\author{
Enrique Colorado Olivares ${ }^{1}$, José Luis Olivares-Romero², Felipe Barrera-Méndez ${ }^{2,3 *}$ \\ ${ }^{1}$ Universidad Veracruzana, Xalapa, Veracruz, Mexico. \\ ${ }^{2}$ Red de Estudios Moleculares Avanzados, Instituto de Ecología AC, Xalapa, Veracruz, Mexico. \\ ${ }^{3}$ Cátedra CONACYT en el Instituto de Ecología AC, Xalapa, Veracruz, Mexico.
}

*Corresponding author: e-mail: felipe.barrera@inecol.mx

Received January 15 ${ }^{\text {th }}, 2018$; Accepted May $18^{\text {th }}, 2018$.

DOI: http://dx.doi.org/10.29356/jmcs.v62i3.452

\begin{abstract}
The use of biodegradable polymers to encapsulate fertilizers is one of the main tools that help to prevent them to get carried away by the irrigation water, since phosphate based fertilizers are highly soluble. Indeed, this technology might improve productivity and reduce both costs and environmental pollution. In this work potassium phosphate was encapsulated in chitosan, which is one of the most abundant natural and biodegradable polymers widely applied in agriculture for plant defense and yield increase, applying the encapsulation method of spray drying to provide a high encapsulation efficiency rates. A $2^{\mathrm{k}}$ factorial design was implemented to evaluate the effect of the different operational parameters of the spray dryer on the particle size, measured by scan electronic microscopy, then it was obtained the average particle sizes to be between 1.08 to $2.04 \mu \mathrm{m}$. The release of $\mathrm{KH}_{2} \mathrm{PO}_{4}$ from chitosan spheres of different sizes was performed in Milli-Q water and was measured using the conductometry technique. The experiments revealed that the parameter with the greatest effect was the feed rate, and that the system with the smallest particle size obtained $(1.08 \mu \mathrm{m})$ showed a slower release without losing an important amount of encapsulation efficiency.

Keywords: Microencapsulation; Chitosan; Fertilizer; Phosphate; Spray Dryer.

Resumen. La encapsulación de fertilizantes en polímeros biodegradables es una de las principales herramientas empleadas que ayudan a prevenir que estos sean arrastrados por el agua de riego debido a que los fertilizantes base fosfato son extremadamente solubles. Estas partículas podrían mejorar la productividad y al mismo tiempo reducir costos y contaminación ambiental. En este trabajo se encapsuló fosfato de potasio en quitosano, uno de los polímeros naturales bioedegradables más abundantes ampliamente aplicados en agricultura para defensa e incremento de producción, aplicando el método de secado por aspersión para obtener altas efíciencias de encapsulación. Se implementó un diseño $2^{\mathrm{k}}$ para evaluar el efecto de los diferentes parámetros de operación del secador por aspersión sobre el tamaño de partícula, medido mediante microscopía electrónica de barrido, después se obtuvo que el tamaño promedio de partícula se encontró entre 1.08 to $2.04 \mu \mathrm{m}$. La liberación del $\mathrm{KH}_{2} \mathrm{PO}_{4}$ de las esferas de quitosano de diferentes tamaños se realizó en agua Milli-Q y fue medida usando la técnica de conductimetría. Los experimentos revelaron que el parámetro con el mayor efecto fue el flujo de alimentación, y que el sistema con el menor tamaño de partícula obtenido $(1.08 \mu \mathrm{m})$ mostró una liberación más lenta sin perder una importante cantidad de eficiencia de encapsulación. Palabras clave: Microencapsulación; Quitosano; Fertilizante; Fosfato; Secador por aspersión.
\end{abstract}




\section{Introduction}

The supply of food for a growing population all over the world is one of the main endeavors that the farming sectors are facing. In this context, agriculture plays a significant role in meeting such demands, which has also led to an increasing dependence on chemical fertilizers and pesticides [1]. Chemical fertilizers are industrially manipulated substances, composed of nitrogen, phosphorus, and potassium, that help to substantially increase food production. Phosphorus, which supplies between 0.1 to 0.4 percent to the plant's dry extract, plays an important role in the energy transfer. It is essential for both photosynthesis and chemicalphysiological processes, also is useful for the development of tissues. Phosphorus is deficient in most natural or agricultural soils, in addition that its fixation limits its availability to plants [2]. In general, $60 \%$ to $90 \%$ of the total applied fertilizer is lost and only from $10 \%$ to $40 \%$ is taken up by plants [3]. The application of fertilizers in excess in order to compensate the low uptake by the plants results costly and may have other environmental impacts. Due to deficient uptake of these chemical fertilizers by plants, the remaining fraction reach into water bodies through rainwater, causing eutrophication and affecting living beings [4]. In recent years, in agriculture there has been a growing interest in the implementation of controlled released fertilizer systems as a promissory alternative to improve the performance of several usage aspects of fertilizers [5].

The main advantages of these systems include: a constant supply of nutrients for the plants; a lower frequency of applications; reduced loses by lixiviation and volatilization; elimination of root damage by high salts concentration; easier management of fertilizers; reduction in environmental pollution; and lowered production costs [6]. Chitosan has been widely used due to their properties (antibacterial, antifungal, antiviral, growth stimulation, and resistance capacity), and because it is a suitable polymer to be a carrier [7]. Chitosan is one of the biodegradable polymers, which is abundant available in nature. This polysaccharide has widely been used in biomedical, pharmaceutical and agricultural fields due to its biocompatibility, non-toxicity and biodegradability [8]. For example, Harris et al encapsulated tramadol in chitosan for controlled release to know the abilities of chitosan as an encapsulating medium [9]. Also, Lopez-Mora et al evaluated the antifungal activity of the chitosan in Alternaria alternata development in relation to mycelial growth, germination and sporulation of Mango during storage [10]. Lastly, Tokárová et al, designed chitosan microspheres by spray drying and studied systematically the effects of different factors, including the chitosan cross-linking ratio (using tripolyphosphate as the cross-linking agent), nanoparticle loading in the polymer matrix, and the internal structure of the microspheres on the in vitro release kinetics. There are currently few studies focused on the design of controlled release systems of fertilizers, in particular using potassium phosphate in an encapsulating medium with chitosan [11].

In this work, particles of chitosan containing potassium phosphate were obtained by spray-drying as an encapsulation method. The goal of these capsules is to achieve a controlled fertilizer release mechanism to prolong the availability of the active ingredient for the longest possible time, decreasing the amount of fertilizer that is carried away by water.

\section{Experimental}

\section{Materials and Methods}

Low molecular weight chitosan (50,000-190,000 Da based-on viscosity, Sigma-Aldrich), Acetic acid, glacial (Sigma-Aldrich) and potassium phosphate monobasic, crystal (J. T. Baker).

Three experiment designs were implemented for this study: In the first one, in order to choose a formulation that yields dried powder with the best conditions (waste of product, time of production, humidity of the powder, shape of particles, etc.) 5 formulations consisting in different rates of carrier/fertilizer were dried at same conditions; in the second one, using the chosen formulation, different operational conditions were tested to find what variables are the most important to determinate the particle size of the powder; finally, on the third one, five powders that yielded different particle sizes where chosen to obtain their release profiles in water and evaluate the influence of the particle size on the fertilizer release speed. 
Preparation of Stock Solutions. The stock solutions used in the experiments were prepared as follows: A solution of chitosan $1 \% \mathrm{w} / \mathrm{v}$ was prepared dissolving $1 \mathrm{~g}$ of chitosan in approximately $75 \mathrm{~mL}$ of aqueous solution of acetic acid $1 \% \mathrm{v} / \mathrm{v}$ overnight. Once the chitosan was completely dissolved, it was taken to a final volume of $100 \mathrm{~mL}$. The chitosan solution was filtered with Whatman paper no. 1 to remove impurities and was stored in refrigeration. The stock solution of the active ingredient was prepared dissolving $1 \mathrm{~g}$ of potassium phosphate in approximately $75 \mathrm{~mL}$ of Milly-Q water and then taken to a final volume of $100 \mathrm{~mL}$.

Encapsulation of fertilizer and evaluation the formulations.Table 1 shows the different formulations dried using the Spray Drying technique on a Yamato dryer, model ADL3115 in order to choose the one that yields the bigger amount of dry powder in the less time. The parameters used were temperature $=$ $150^{\circ} \mathrm{C}$, air pressure $=0.2 \mathrm{MPa}$, feed rate $=3.6 \mathrm{~mL} / \mathrm{min}$, and steam extraction rate $=10 \mathrm{~m}^{3} / \mathrm{min}$.

Table 1. Fertilizer formulations dried by Spray Drying.

\begin{tabular}{|c|c|c|c|c|}
\hline $\begin{array}{c}\text { Carrier } \\
/ \text { Fertilizer Ratio }\end{array}$ & $\begin{array}{l}\text { Chitosan 1\% w/v } \\
\text { Solution (mL) }\end{array}$ & $\begin{array}{l}\text { Potassium Phosphate } \\
1 \% \text { w/v Solution }(\mathrm{mL})\end{array}$ & $\begin{array}{l}\text { Milli-Q Water } \\
\text { (mL) }\end{array}$ & $\begin{array}{c}\text { Final } \\
\text { Volume } \\
(\mathrm{mL})\end{array}$ \\
\hline $5 / 2$ & 25 & 10 & 65 & 100 \\
\hline $1 / 1$ & 25 & 25 & 50 & 100 \\
\hline $5 / 1$ & 25 & 5 & 30 & 100 \\
\hline $1 / 2$ & 25 & 50 & 25 & 100 \\
\hline
\end{tabular}

Evaluation of the Spray Dryer parameters. A $2^{\mathrm{k}}$ factorial design was implemented to evaluate the particle size of the encapsulated fertilizer, and also it was analyzed the effect of all the parameters that the Spray Dryer controls. The four parameters tested were: drying temperature, air pressure, feed rate, and steam extraction rate. Table 2 shows the values for the levels used of each variable. Such levels were chosen because those were the limit conditions where the solutions could still be totally dried (e.g. $10 \mathrm{~m}^{3} / \mathrm{min}$ is the maximum extraction rate the equipment is able to achieve, and going under $6 \mathrm{~m}^{3} / \mathrm{min}$ would leave humidity in the powder).

Table 2. Levels for the experimental variables.

\begin{tabular}{|c|c|c|}
\hline Factor & \multicolumn{2}{|c|}{ Experimental Domain } \\
\hline & Level $(-)$ & Level $(+)$ \\
\hline Temperature & $120^{\circ} \mathrm{C}$ & $150^{\circ} \mathrm{C}$ \\
\hline Air Pressure & $0.2 \mathrm{MPa}$ & $0.4 \mathrm{MPa}$ \\
\hline Feed Rate & $1.4 \mathrm{~mL} / \mathrm{min}$ & $3.6 \mathrm{~mL} / \mathrm{min}$ \\
\hline Extraction Rate & $6 \mathrm{~m}^{3} / \mathrm{min}$ & $10 \mathrm{~m}^{3} / \mathrm{min}$ \\
\hline
\end{tabular}

Release Profile and encapsulation efficiency. Five systems with different particle sizes were chosen from the results of the $2^{\mathrm{k}}$ factorial experiments in order to evaluate the effect of the particle diameter on the release profile. The particle sizes tested were $2.04 \mu \mathrm{m}, 1.81 \mu \mathrm{m}, 1.50 \mu \mathrm{m}, 1.31 \mu \mathrm{m}$, and $1.08 \mu \mathrm{m}$. Such systems were chosen by picking the biggest and the smallest particle sizes obtained, as well as 3 sizes between the extremes, with intervals of approximately $0.24 \mu \mathrm{m}$. Then $140 \mathrm{mg}$ of each system were weighted and put in dialysis tubes of $12-14 \mathrm{kDa}$ to be dialysed in $40 \mathrm{~mL}$ of Milli-Q water at $20{ }^{\circ} \mathrm{C}$. The phosphate concentration in the release medium was measured by the conductometry technique in order to build a calibration curve (concentration vs conductivity), using a Hach conductometer, model Sension 156. As positive control, $40 \mathrm{mg}$ of potassium phosphate were dialysed, representing a $100 \%$ of encapsulation efficiency. As negative controls, $100 \mathrm{mg}$ of pure chitosan of each particle size were dialysed, representing the carrier fraction of each system that could contribute to an increase in the conductivity of the water. These 
contributions were subtracted from the conductivities of their respective chitosan+phosphate systems to calculate the conductivity corresponding only to the phosphate fraction and all experiments were performed twice. The encapsulation efficiency $(\% \mathrm{E})$ can be obtained using the following equation:

$$
\% E=\frac{M_{R}}{M_{0}} * 100
$$

where $\mathrm{M}_{0}$ is the phosphate mass used in the encapsulation and $\mathrm{M}_{\mathrm{R}}$ is the phosphate mass released during the experiment.

\section{Results and discussions}

Formulation tests. The pictures of the powder particles were obtained by scan electronic microscopy (SEM) using a JEOL microscope, model JSM-IT300LV. As presented in Fig. 1, each Chitosan/phosphate ratio showed different morphology: Ratio 1/1 had its particles heavily imploded, giving them a ring shape; the particles obtained by drying the $1 / 2$ ratio presented a semi spherical morphology. This formulation showed a higher humidity inside the spry dryer and in the final product; Ratio 5/1 showed more rounded particles with a bigger size. During the drying process of this formulation a chitosan film was deposited on the walls of the spry dryer, which represents loses of product; finally, ratio 5/2 presented collapsed spheres as well, due to the implosion of the particles, but without any further complication during the drying process. Given this, the ratio $5 / 2$ was chosen as the formulation to be used in the rest of the experiments because it yields semi spherical particles without product loses nor excess of humidity.

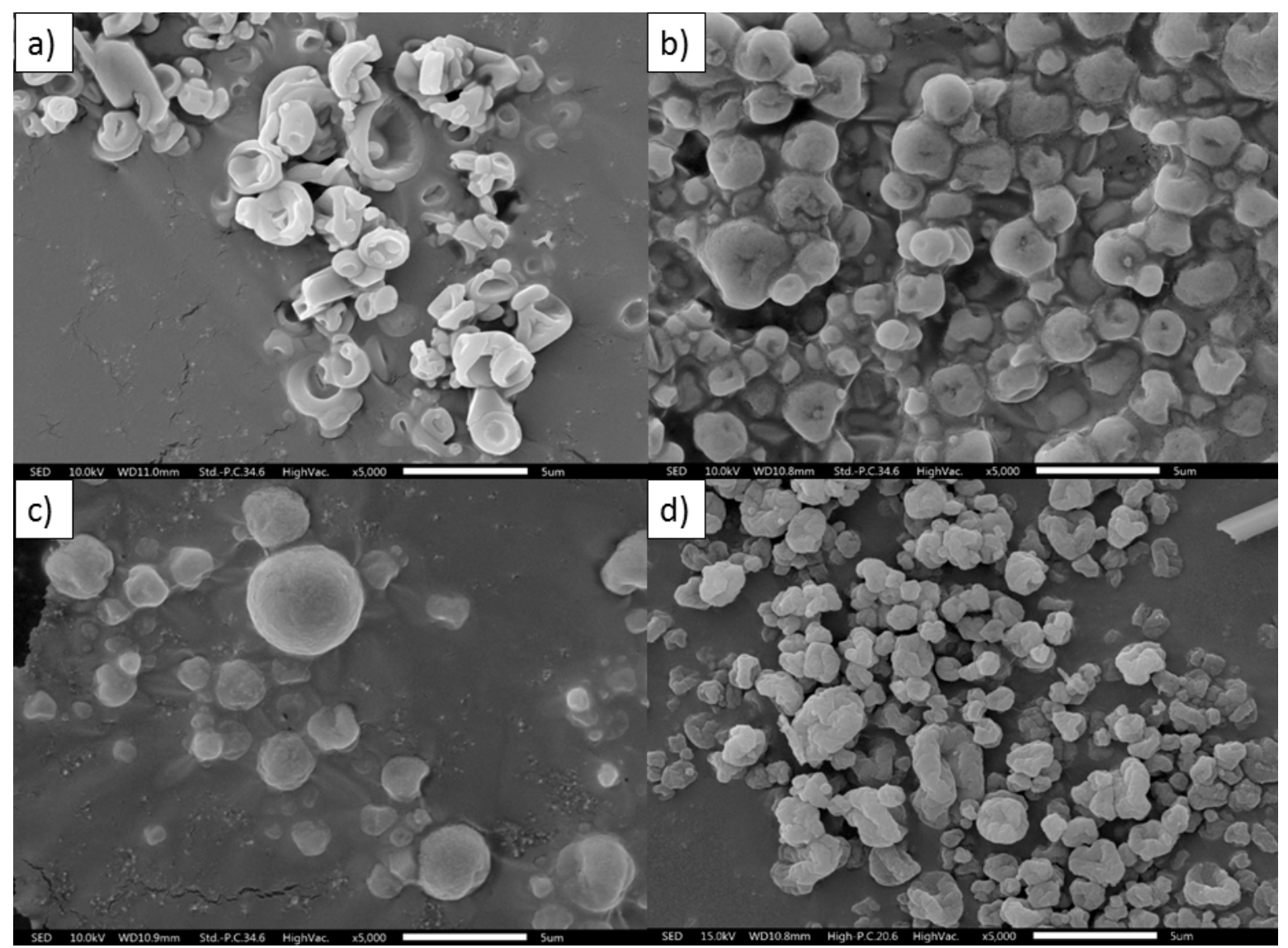

Fig. 1. Morphologies of the different dried chitosan/potassium phosphate rates at 5000X: a) 1/1, b) 1/2, c) 5/1, d) $5 / 2$. 
Statistical analysis. SEM was used to analyze the powders obtained in each iteration in order to calculate the particle size. 200 particles of each treatment were measured individually utilizing the Image J® software. Table 3 presents the results for these measurements. The statistical analysis was performed using the Minitab ${ }^{\circledR}$ software, which yielded the graph shown on Fig. 2.

Table 3. Particle size measured for each iteration.

\begin{tabular}{|c|c|c|c|c|c|}
\hline Iteration & $\begin{array}{c}\text { Temperature } \\
\left({ }^{\circ} \mathrm{C}\right)\end{array}$ & $\begin{array}{c}\text { Air Pressure } \\
(\mathrm{MPa})\end{array}$ & $\begin{array}{c}\text { Extraction Rate } \\
\left(\mathrm{m}^{3} / \mathrm{min}\right)\end{array}$ & $\begin{array}{l}\text { Feed Rate } \\
(\mathrm{mL} / \mathrm{min})\end{array}$ & $\begin{array}{c}\text { Particle Size } \\
(\mu \mathrm{m})\end{array}$ \\
\hline 1 & 120 & 0.2 & 6 & 1.4 & 1.36 \\
\hline 2 & 150 & 0.2 & 6 & 1.4 & $1.81 *$ \\
\hline 3 & 120 & 0.4 & 6 & 1.4 & 1.45 \\
\hline 4 & 150 & 0.4 & 6 & 1.4 & $1.31 *$ \\
\hline 5 & 120 & 0.2 & 10 & 1.4 & $1.08 *$ \\
\hline 6 & 150 & 0.2 & 10 & 1.4 & 1.18 \\
\hline 7 & 120 & 0.4 & 10 & 1.4 & 1.54 \\
\hline 8 & 150 & 0.4 & 10 & 1.4 & 1.35 \\
\hline 9 & 120 & 0.2 & 6 & 3.6 & 1.30 \\
\hline 10 & 150 & 0.2 & 6 & 3.6 & 1.55 \\
\hline 11 & 120 & 0.4 & 6 & 3.6 & 1.87 \\
\hline 12 & 150 & 0.4 & 6 & 3.6 & 1.88 \\
\hline 13 & 120 & 0.2 & 10 & 3.6 & $2.04 *$ \\
\hline 14 & 150 & 0.2 & 10 & 3.6 & 1.34 \\
\hline 15 & 120 & 0.4 & 10 & 3.6 & 1.46 \\
\hline 16 & 150 & 0.4 & 10 & 3.6 & $1.50 *$ \\
\hline
\end{tabular}

*Treatments chosen for the phosphate release experiments.

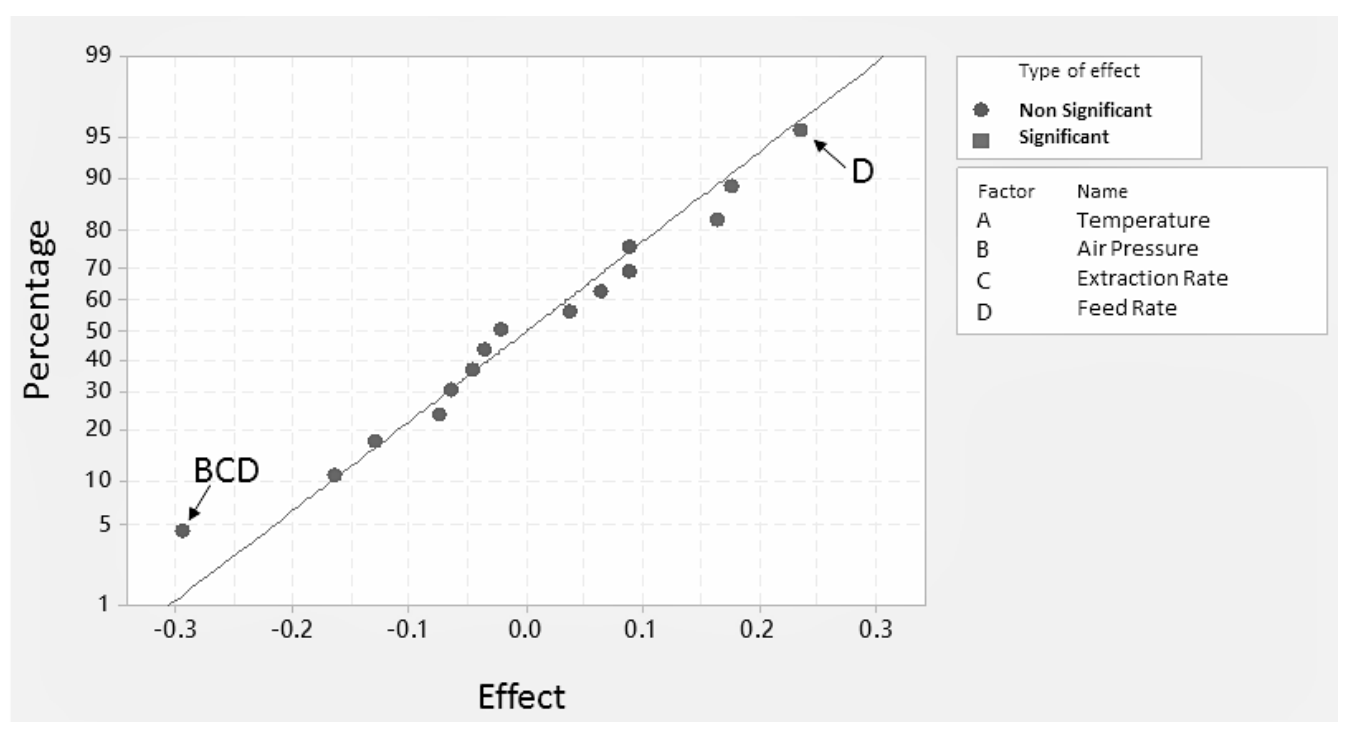

Fig. 2. Effect of the variables tested on the particle size. 
Fig. 2 shows a normal probability plot of the effects, where the positive values have a directly proportional effect on the particle size, while the negative values have an inversely proportional effect, and those farther from 0 are statistically significant. The shape of the dots differs between statistically significant effects and statistically insignificant effects. Through the interpretation of the graph, the effect of feed flow (D) shows to be the most important effect on particle size, along with the triple interaction of the effects of air pressure, extraction flow and feed flow (BCD). In addition, the graph shows the direction of each effect, having the feed flow a positive standardized effect, meaning that the process changes from the low to the high level of the factor increases the response variable (a bigger feed rate will increase the particle size). In contrast, the triple interaction has negative effects, meaning that when those effects in its combination increase, the response variable decreases.

By taking account the four variables, the model has a $\mathrm{R}^{2}$ of $100 \%$, but none of them happened to have a significant effect, being the temperature (A) the one with the lesser magnitude. This can be explained because the temperatures tested has an interval so low that doesn't show a statistical difference, but being that under $120^{\circ} \mathrm{C}$ the powder would not dry completely, and over $150^{\circ} \mathrm{C}$ the chitosan ended melted, no other temperatures could be used.

Conductometry. The Fig. 3 shows the release profiles for the systems tested, while Fig. 4 shows the calibration curve used to calculate the concentration of phosphate in the water, which had a $\mathrm{R}^{2}$ of 0.9995 . While the control reaches the peak phosphate concentration by the second hour, the graph shows that the smallest particle size retards the IA liberation for the longest time (release of the $100 \%$ of the load until the $9^{\text {th }}$ hour) with the lowest burst release, while the biggest particle size has the quickest liberation time (release of the $100 \%$ of the load by the $5^{\text {th }}$ hour) and presenting a high burst release. In perspective, when the system with the biggest particles had already released all its encapsulated fertilizer, the system with the smallest particles still had about $13 \%$ of its fertilizer load. The middle sizes have a similar behavior among them, having released the $100 \%$ of their load in 7 to 8 hours. This experiment helps to understand which system would release the fertilizer for the longest time but nothing more, since the conditions in the field would be very different given that the presence of water would not be constant, nor the release medium, and the changes in the $\mathrm{pH}$ would affect the solubilization of the chitosan particles.

\section{Release profiles}

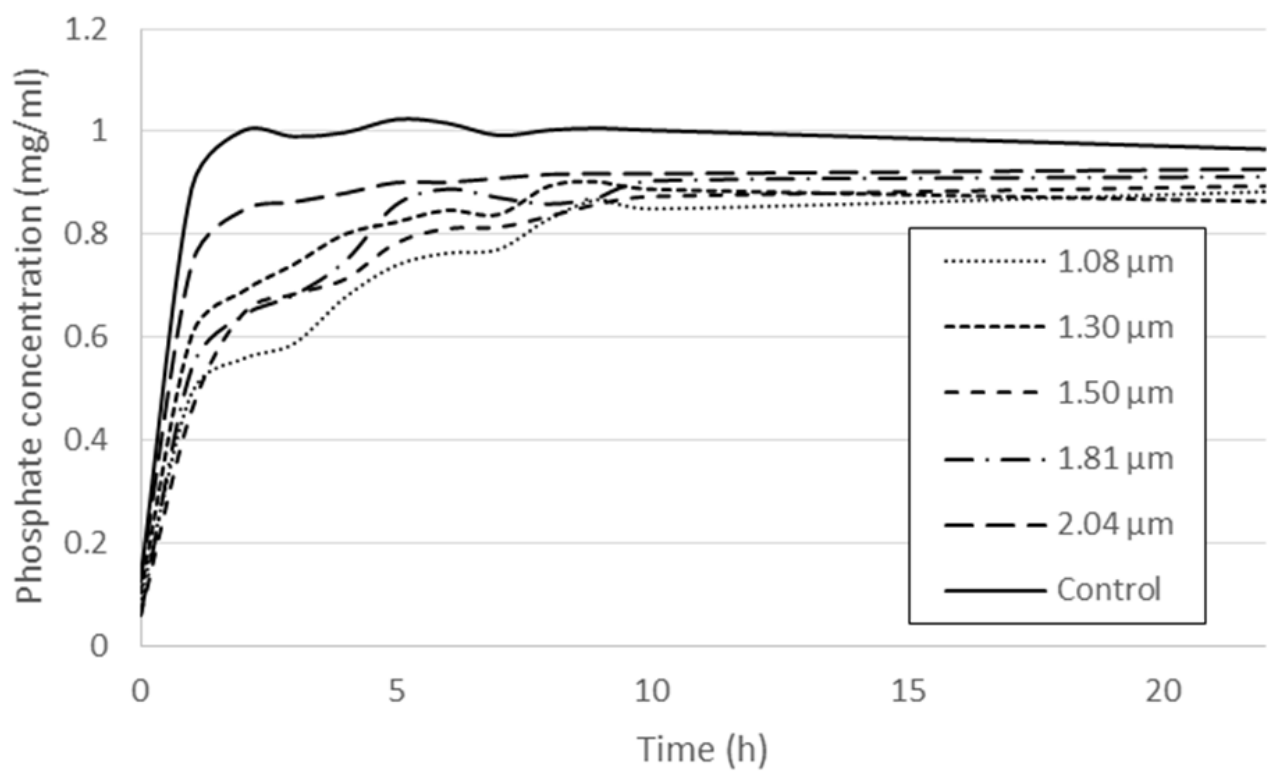

Fig. 3. Calibration curve and phosphate release profiles. 


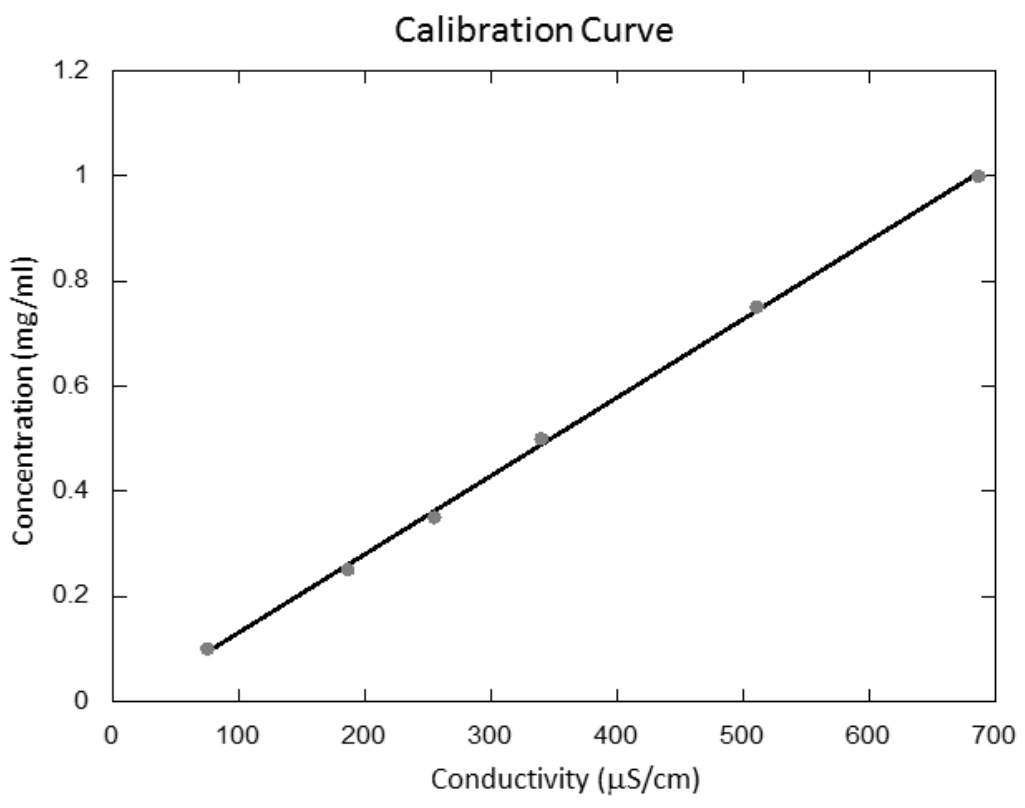

Fig. 4. Calibration curve of phosphate concentration $(\mathrm{mg} / \mathrm{ml})$ vs conductivity $(\square \mathrm{S} / \mathrm{cm})$.

Table 4 shows the encapsulation efficiency for the different systems tested. It could be appreciated a correlation between the particle size and the encapsulation efficiency, being that the bigger the particle, the bigger the amount of potassium phosphate encapsulated. Nevertheless, the interval of sizes is not big enough to represent a statistical difference. Every system presented high encapsulation efficiencies (around 90\%).

Table 4. Encapsulation efficiency for the systems tested.

\begin{tabular}{|c|c|}
\hline Particle Size ( $\boldsymbol{\mu m})$ & Encapsulation Efficiency \\
\hline 1.08 & $88.38 \%$ \\
\hline 1.31 & $90.29 \%$ \\
\hline 1.50 & $89.37 \%$ \\
\hline 1.81 & $91.08 \%$ \\
\hline 2.04 & $92.67 \%$ \\
\hline
\end{tabular}

\section{Conclusions}

The potassium phosphate fertilizer was encapsulated at high encapsulation efficiencies, which is inherent to the spray drying encapsulation technique. Given the short range of setting for the parameters of the spray dryer that yielded dry semi spherical chitosan particles, the statistical study shows that, since the only significant effect on the particle size is the triple interaction of the air pressure with the feed and extraction rates, the change in the temperature has no effect for these systems. Nevertheless, the combination of settings yielded a range of sizes that enabled to test the effect of the particle size on the release rate of the systems. Even if the graph shows that all the systems released the $100 \%$ of their load within the first 10 hours, this does not mean that such release would occur on the field; the quick release was due to the small amount of fertilizers dialyzed into a relative big amount of medium. This action allowed us to estimate the behavior of the each system and compare them with others in a short time ( 24 hours for each run) but does not let predict 
their behavior on the field. The conductometry experiments showed that the smallest particle size $(1.08 \square \mathrm{m})$ retarded the liberation of the fertilizer for the most time, losing only $4.29 \%$ in encapsulation efficiency compared with the system that encapsulated the most amount of potassium phosphate. Further experimentation with plants in vitro and in field is ongoing to determine the real advantages of these release systems over conventional fertilizers. The potassium phosphate encapsulation in chitosan micro spheres has a great potential because of its encapsulation efficiency reached and the release rate in comparison with the control.

\section{Acknowledgements}

The authors thank to Greta Hanako Rosas Saito (Instituto de Ecología) for the technical support on the acquisition of SEM images. This work was financed by the Consejo Nacional de Ciencia y Tecnología (CONACYT) Grant: 248760.

\section{References}

1. Santos, V. B.; Araujo, S. F.; Leite, L. F.; Nunes, L. A.; Melo, J. W.; Geoderma 2012, 170, 227. DOI:10.1016/j.geoderma.2011.11.007

2. FAO; ifa 2002, 4, 77

3. Bhardwaj, D.; Ansari, M. W.; Sahoo, R. K.; Tuteja, N.; Microbial Cell Factories 2014, 13, 66. DOI: https://doi.org/10.1186/1475-2859-13-66

4. Youssef, M. M.; Eissa, M. F.; E3 J Biotechnol. Pharm Res 2014, 5, 1.

5. Messaa, L. L.; Froesb, J. D.; Souzab, C. F.; Faez R.; Quim. Nova 2016, 10, 1215. DOI: http://dx.doi.org/10.21577/0100-4042.20160133

6. Joseph, T.; Morrison, M.; A Nanoforum Report 2006.

7. Lárez, C; UDO Agricola 2008, 8, 22.

8. Ahmad, N. N. R.; Fernando, W. J. N.; Uzir, M. H.; Biosystems Engineering 2015, 129, 78-86. DOI: https://doi.org/10.1016/j.biosystemseng.2014.09.015

9. Harris,R.; Paños, I; Acosta, N; Heras, A; Journal Of Controlled Release 2008, 132, e76-e77. DOI: https://doi.org/10.1016/j.jconrel.2008.09.069

10. Lopez-Mora, L. I.; Gutiérrez-Martínez, P.; Bautista-Baños, S.; Jiménez-García, L. F.; \& ZavaletaMancera, H. A.; Chapingo Serie Horticultura 2013, 3, 315-331. DOI: 10.5154/r.rchsh.2012.07.038

11. Tokárová, V.; Kašpar, O.; Knejzlík, Z.; Ulbrich, P.; \& Štěpánek, F; Powder Technology 2013, 235, 797805. DOI: 10.1016/j.powtec.2012.12.005 